\title{
A ARTICULAÇÃo ECONÔMICA DE ESPAÇOS LOCAIS AO MERCADO GLOBAL DE COMMODITIES: O EXEMPLO DO MUNICÍPIO DE UBERLÂNDIA (MG)
}

\author{
Denise Leonardo Custodio Machado de OLIVEIRA ${ }^{1}$
}

Silvia SELINGARDI-SAMPAIO²

\begin{abstract}
Resumo
A partir dos anos 1970, a economia mundial foi se tornando cada vez mais globalizada, e uma decorrência foi o aprofundamento da inserção do Brasil na nova ordem econômica mundial como exportador de commodities agrícolas e agroindustriais. É em meio a este contexto que se analisa, neste artigo, a expansão das exportações de produtos específicos, tais como os do complexo soja, de carnes e de couros, que ocorre correlatamente a uma crescente especialização produtiva do território no município de Uberlândia (MG). Em um recorte temporal que vai de 2000 a 2014, são identificados os principais produtos agrícolas e agroindustriais exportados por Uberlândia e os mercados receptores mais significativos. Assim, podem ser reconhecidas e mapeadas as articulações econômicas que o espaço local estrutura e sustenta com vários países e continentes, as quais contribuem para caracterizar o Brasil como país exportador de commodities.
\end{abstract}

Palavras-chave: Uberlândia. Globalização. Exportação de soja, carnes e couros. Mercado globalizado.

\section{THE ECONOMIC ARTICULATION OF LOCAL SPACES IN THE GLOBAL COMMODITIES MARKET: THE EXAMPLE OF THE MUNICIPALITY OF UBERLÂNDIA (MG)}

\begin{abstract}
Since the 1970s, the world economy became increasingly globalized, and one consequence has been Brazil's growing presence in the new world economic order as an exporter of agricultural and agro-industrial commodities. This article analyses the expansion of exports of specific commodities within this context, such as soybeans, meat and leather products, this expansion correlated with the growing production specialisation of the territory in the city of Uberlândia (MG). The article identifies the main agricultural and agroindustrial products exported by Uberlândia and the most significant recipient markets during the time period 2000-2014, allowing economic articulation of local structures and frameworks in Uberlândia to be recognised and mapped across countries and continents. Delineation of these local factors contributes to the characterisation of Brazil as an exporter of commodities.
\end{abstract}

\footnotetext{
${ }^{1}$ Doutora em Geografia pela universidade Estadual Paulista, UNESP, Rio Claro. E-mail: denisecustodiooliveira@gmail.com

2 Universidade Estadual Paulista, Rio Claro/Programa de Pós-Graduação em Geografia. E-mail: triesses2@gmail.com
} 
Key-words: Uberlândia. Local space. Export of soybeans, meats and leather mills. Globalized market.

\section{LA ARTICULACIÓN ECONÓMICA DE LOS ESPACIOS LOCALES CON EL MERCADO GLOBAL DE PRODUCTOS BÁSICOS: EL EJEMPLO DE LA CIUDAD DE UBERLÂNDIA (MG)}

\section{Resumen}

A partir de la década de 1970, la economía mundial se globalizó cada vez más, y una consecuencia fue la profundización de la inserción de Brasil en el nuevo orden económico mundial como exportador de productos agrícolas y agroindustriales. En este contexto, este artículo analiza la expansión de las exportaciones de productos específicos, como los del complejo de soja, carne y cuero, que se produce junto con una creciente especialización productiva del territorio en la ciudad de Uberlândia (MG) En un período de tiempo que va de 2000 a 2014, se identifican los principales productos agrícolas y agroindustriales exportados por Uberlândia y los mercados receptores más importantes. Por lo tanto, las articulaciones económicas que el espacio local estructura y sostiene con varios países y continentes pueden reconocerse y cartografiarse, lo que contribuye a caracterizar a Brasil como un país que exporta productos básicos.

Palabras clave: Uberlândia. Globalización Exportaciones de soja, carne y cuero. Comercio global.

\section{INTRODUÇÃO}

O presente artigo objetiva analisar a articulação econômica do município de Uberlândia (MG) ao mercado globalizado de commodities, desde princípios do século XXI, através de quatro cenários - 2001, 2006, 2010 e 2014 -, os quais abrangem o período de aprofundamento da inserção do Brasil na economia global como exportador de commodities agrícolas e agroindustriais.

O município em questão, localizado na mesorregião do Triângulo Mineiro/Alto Paranaíba, no Estado de Minas Gerais, possui acentuada tradição nas atividades agropecuária e agroindustrial, as quais, após os anos 1970, conheceram intensa expansão, em escala nacional. Os processos de modernização e de industrialização da agricultura, que atingiram as áreas de cerrado a partir da citada década, propiciaram a especialização produtiva do território em gêneros agropecuários e agroindustriais, com a instalação de grandes empresas, atualmente vinculadas ao agronegócio. 
Neste contexto, desde o início da década de 2000, com a crescente participação do Brasil no comércio global de commodities, Uberlândia, a exemplo de outras localidades, encontra-se articulada ao mercado globalizado, através das exportações, sobretudo, de produtos do complexo soja, de carnes e de couros.

Assim sendo, para atingir-se o objetivo proposto, no primeiro segmento do texto são abordados aspectos teóricos relativos à articulação das escalas geográficas local e global, no contexto da globalização da economia capitalista. Com base nas exportações do complexo soja, de carnes e couros, referentes ao período de 2000 a 2014, no segundo segmento é analisada a participação de Uberlândia no comércio internacional de commodities. No terceiro segmento, a partir dos principais espaços de destino das exportações uberlandenses relativas aos anos de 2001, 2006, 2010 e 2014 - analisa-se a articulação do espaço local ao mercado globalizado de commodities. Nas considerações finais, são feitas algumas reflexões a respeito da atual conjuntura econômica, nacional e internacional, no que tange ao comércio globalizado de commodities, e seus efeitos em localidades (tais como Uberlândia), cujas economias se encontram atreladas ao agronegócio.

O procedimento metodológico adotado consiste em análise bibliográfica referente à abordagem sobre a relação local e global, e à globalização da economia; ao levantamento junto à base de dados Agrostat, do Ministério da Agricultura, Pecuária e Abastecimento (MAPA), para informações relativas à pauta exportadora brasileira; à consulta à plataforma Dataviva, para obtenção de dados sobre as exportações de Uberlândia e também do Brasil; ao banco de dados do Centro Industrial e Empresarial de Minas Gerais (CIEMG), para informações relativas às empresas agroindustriais situadas no município em questão, além de pesquisa direta junto a alguns dos estabelecimentos, bem como ao sítio eletrônico dos mesmos.

\section{AS ESCALAS LOCAL E GLOBAL}

O processo de globalização, desencadeado nas últimas décadas do século $\mathrm{XX}$, trouxe para o cerne do debate acadêmico a abordagem a respeito das 
dimensões local e global. No âmbito da Geografia, as análises se voltam para a articulação das escalas geográficas - local, nacional e global - e, particularmente na Geografia Econômica, surgiram trabalhos que tratam desta temática.

A obra "Spatial Divisions of Labour", de 1984, da geógrafa britânica Doreen Massey, foi um dos primeiros estudos que trouxeram à tona a discussão da relação local-global, demonstrando que, se de um lado cada local é único e diferente, de outro só pode ser entendido se analisado no contexto global. Neste sentido, cabe aqui a afirmação do filósofo Michel Serres (1990, apud SANTOS, 2006, p. 313) de que '[...] nossa relação com o mundo mudou. Antes, era locallocal; agora é local-global [...]'.

Assim sendo, o espaço local, por si só, não permite explicar as causas de sua configuração socioeconômica e produtiva, se analisado isoladamente, ou seja, sem que se considere as relações estabelecidas com outras escalas espaciais. Tal propósito requer o entendimento tanto dos aspectos endógenos, inerentes à localidade, como de fatores ou eventos exógenos, advindos de outras esferas. Todas essas diretrizes acabam convergindo para a adoção de uma abordagem multiescalar, que associe diferentes níveis escalares de análise (considerados como interdependentes e com interpenetrações mútuas), e que busque uma explanação integradora das ações e dos eventos considerados. Selingardi-Sampaio (2009, p. 28) destaca a importância da abordagem multiescalar nas análises geográficas, ao afirmar que:

[...] regiões e outras localidades (ou territórios locais), ao mesmo tempo que desenvolvem um conjunto próprio de eventos específicos, de natureza endógena, e a si restritos, também recebem influxos de eventos ocorridos e agentes operantes em escalas nacional, supranacional e global [...] eventos e ações estes centrados na lógica e na dinâmica do modo de produção capitalista, mas que, dialeticamente, se territorializam em escalas local e regional [...].

A atual divisão internacional do trabalho, que caracteriza a economia globalizada, envolve vários países e continentes, ocorrendo, pois, em escala global. Todavia, se nem todos os países participam do mercado globalizado, ou se participam em condições desiguais, é fato inconteste que aqueles que 
vivenciam tal participação o fazem através de localidades que se inserem na divisão territorial do trabalho.

Para Santos (2006, p. 339), no contexto do processo de globalização econômica, haveria uma ordem global e uma ordem local. Conforme o autor:

A ordem global funda as escalas superiores ou externas à escala do cotidiano [...] A ordem local funda a escala do cotidiano [...] A ordem global é 'desterritorializada', no sentido de que separa o centro da ação e a sede da ação. Seu 'espaço', movediço e inconstante, é formado de pontos, cuja existência funcional é dependente de fatores externos. A ordem local [...] é a do espaço banal, espaço irredutível [..] porque reúne numa mesma lógica interna todos os seus elementos: homens, empresas, instituições, formas sociais e jurídicas e formas geográficas.

De acordo com Silveira (1996, p. 66), para que a ordem global se imponha à ordem local, é preciso que haja “[...] a profusão de discursos e imagens que, contribuindo para criar a 'necessidade' e a vocação pela globalização nos lugares, facilita a instalação e a obediência às novas organizações, normas e objetos”.

Por outro lado, considerar a ideia da globalização como um fenômeno inevitável, tal como analisa Massey (2008), também reforça a imposição da ordem econômica globalizada. Segundo a autora:

[...] a forma específica de globalização que estamos experimentando no momento (capitalista neoliberal, conduzida por multinacionais etc., etc.) é considerada uma e sua única forma. Objeções a essa globalização particular encontram, frequentemente, a irônica réplica de que 'o mundo, inevitavelmente, irá se tornar mais interconectado'. A globalização capitalista torna-se [...] uma manobra discursiva que, de um só golpe, obscurece a possibilidade de visualizar formas alternativas. É a globalização capitalista nesta forma particular que, portanto, é considerada inevitável. (MASSEY, 2008, p. 127-128).

Com a nova ordem mundial capitalista instaurada a partir dos anos 1990, espaços locais articulam-se às esferas nacional e global, tanto pela instalação e/ou intensificação de atividades produtivas de grandes empresas, em geral multinacionais, como pela ampliação do comércio de exportações. Em referência à atuação das empresas no contexto da globalização econômica, 
Santos (2006, p. 205, baseado em Savy e Veltz, 1993) afirma que ‘o novo espaço das empresas é o mundo’.

Assim sendo, o “discurso da globalização como inevitável” a que Massey (2008) se refere, serve, certamente, para justificar a implementação, por parte dos governos nacionais, de políticas de incentivo à atividade de exportação, que acabam por articular as escalas local, nacional e global. Neste sentido, a autora, em referência à participação dos países subdesenvolvidos no mercado globalizado, afirma:

No Sul é esta compreensão do espaço do futuro (como espaço comercial global sem limites) que permite a imposição de programas de ajustamento estrutural e seus substitutos. É esta compreensão da inevitabilidade dessa forma de globalização que torna legítima a imposição de políticas voltadas para a exportação na economia de um país a outro, a priorização das exportações sobre a produção para consumo local. É este discurso, desta forma específica de globalização, que é um importante componente da contínua legitimização da visão de que há um modelo específico de 'desenvolvimento', um caminho para uma forma de 'modernização'. (MASSEY, 2008, p. 128).

Tal discurso, sem dúvida, "vai ao encontro" das estratégias de expansão de grupos econômicos, tais como os vinculados ao agronegócio.

A articulação econômica do Brasil ao mercado internacional ganha um novo dinamismo a partir dos anos 2000. Embora as relações comerciais brasileiras com o exterior tivessem se intensificado já desde meados do século XX - com crescimento da exportação de produtos industrializados -, no período mais recente elas assumem um novo significado, pelo fato de se estabelecerem no contexto de valorização de produtos considerados commodities, tais como os do complexo soja, de carnes e de couros.

Neste sentido, a análise da dimensão espacial local remete à ideia de lugar. Conforme Santos (2006, p. 314): “Cada lugar é, à sua maneira, o mundo. [...] Mas, também, cada lugar, irrecusavelmente imerso numa comunhão com o mundo, torna-se exponencialmente diferente dos demais. A uma maior globalidade, corresponde uma maior individualidade”. Portanto, os eventos que ocorrem em nível mundial repercutem de formas distintas nas diversas localidades, de acordo com as condições ou especificidades locais. Cabe aqui a afirmação de Benko e Pecqueur (2001, p. 38): 
Nosso mundo "global" é assim um mosaico composto de uma multiplicidade de regiões e de localidades, que não são, longe disto, necessariamente equivalentes. Contrariamente às predições mais sombrias, os 'territórios' com suas especificidades não são apagados sob os fluxos econômicos da mundialização.

No caso de Uberlândia, a expansão da atividade agroindustrial, a partir dos anos 1970, juntamente com a privilegiada posição geográfica e a condição de entroncamento rodoferroviário, dentre outros fatores, ensejaram, a partir da década de 2000, a sua articulação à esfera econômica globalizada.

Como afirma Santos (2006, p. 337): "Não existe um espaço global, mas, apenas, espaços da globalização [...] O Mundo, porém, é apenas um conjunto de possibilidades, cuja efetivação depende das oportunidades oferecidas pelos lugares". (destaque do autor). Neste sentido, Santos (1997, p. 50-51) aponta como um dos aspectos que caracterizam os "espaços globalizados", a exacerbação das especializações produtivas.

Os referidos "espaços da globalização" seriam aqueles onde os agentes hegemônicos (tais como empresas e instituições financeiras) se manifestam, conforme as "oportunidades" encontradas nas diversas localidades. Ainda segundo Santos (2006, p. 338): "É o lugar que oferece ao movimento do mundo a possibilidade de sua realização mais eficaz. Para se tornar espaço, o Mundo depende das virtualidades do Lugar”. Cada lugar é, ao mesmo tempo, objeto de uma razão global e de uma razão local, convivendo dialeticamente. (SANTOS, 2006, p. 339).

Em Uberlândia, a especialização produtiva em gêneros agropecuários e agroindustriais foi intensificada pela ação de empresas nacionais e estrangeiras, permitindo que o município tivesse, a partir da década de 2000, um upgrade em sua condição agroindustrial tradicional e se definisse plenamente como um local voltado para a produção e exportação de commodities e, portanto, articulado à escala global (particularmente, aos países asiáticos), o que será analisado a seguir. 


\section{AS EXPORTAÇÕES DE COMMODITIES AGRÍCOLAS E AGROINDUSTRIAIS NO PERÍODO DE 2000 A 2014}

Em meio à trajetória trilhada pela economia brasileira no período em tela, sustentada pela política de fomento ao agronegócio (agente poder público), alguns territórios locais passaram a intensificar sua articulação ao comércio global de commodities.

A respeito das exportações brasileiras, segundo informações do Agrostat (BRASIL, 2016), desde o início dos anos 2000, os produtos do chamado complexo soja (soja em grão, farelo e óleo de soja) constituem-se nos principais artigos de exportação do agronegócio no país, perfazendo 20,0\%, em 2000, e alcançando, em 2014, 32,4\% do total. Cabe ao complexo carnes (carne suína, de aves e bovina), desde 2005, a segunda colocação (quando atingiu 18,7\%), e ao segmento de couros também uma participação importante (a qual correspondeu, até meados dos anos 2000, a $7 \%$ e $9 \%$ das exportações, chegando, porém, ao final do período, com $3 \%$ do total). Embora tenham apresentado uma participação menor em relação aos outros dois (soja e carnes), como se verá, os couros consistem em um dos principais produtos de exportação do município em estudo, o que justifica considerá-los na presente análise. Além destes, outras mercadorias que se destacaram nas exportações nacionais, no período abordado, foram produtos florestais, do complexo sucroalcooleiro e café, e ainda, em menor proporção, cereais, farinhas e preparações.

No que concerne à Uberlândia, com base nas informações do Banco de Dados DATAVIVA, foi possível identificar os produtos exportados pelo município, para o período de 2000 a 2014.

Assim, verificou-se que a pauta exportadora abrange, predominantemente, produtos classificados como básicos (tais como soja em grão, milho em grão, carnes in natura, café) e semimanufaturados (couros e peles curtidos, couros preparados, farelo e óleo de soja, açúcar em bruto), embora também sejam exportados manufaturados (produtos químicos, maquinários, etc.).

Considerando-se o período abordado, verifica-se que os produtos de exportação que mais se destacaram consistem naqueles do chamado complexo 
soja e do segmento couros (peles e couros de animais) e, portanto, vinculados ao agronegócio.

Conforme pode ser observado no gráfico 1, nos primeiros anos da década de 2000, o complexo soja apresentou uma participação entre 31\% e 43\%, atingindo, em 2004, 53,8\% do total exportado. Em 2005 e 2006, alcançou 72\% e, nos anos seguintes, manteve uma participação de $45 \%$ a $65 \%$, totalizando, em 2014, 49,45\% das exportações.

O segmento couros (peles e couros de animais) destacou-se entre os anos de 2000 e 2003, perfazendo de 37,25\% a 50,29\% do total das exportações, vindo a declinar sensivelmente a partir de 2004. Contudo, desde 2011 tal segmento vem recuperando a sua participação nas exportações uberlandenses, chegando, em 2014, a 37,45\% do total. (Gráfico 1).

Gráfico 1- Exportações do complexo soja e de couros por produto - Uberlândia (MG) - 2000 a 2014.

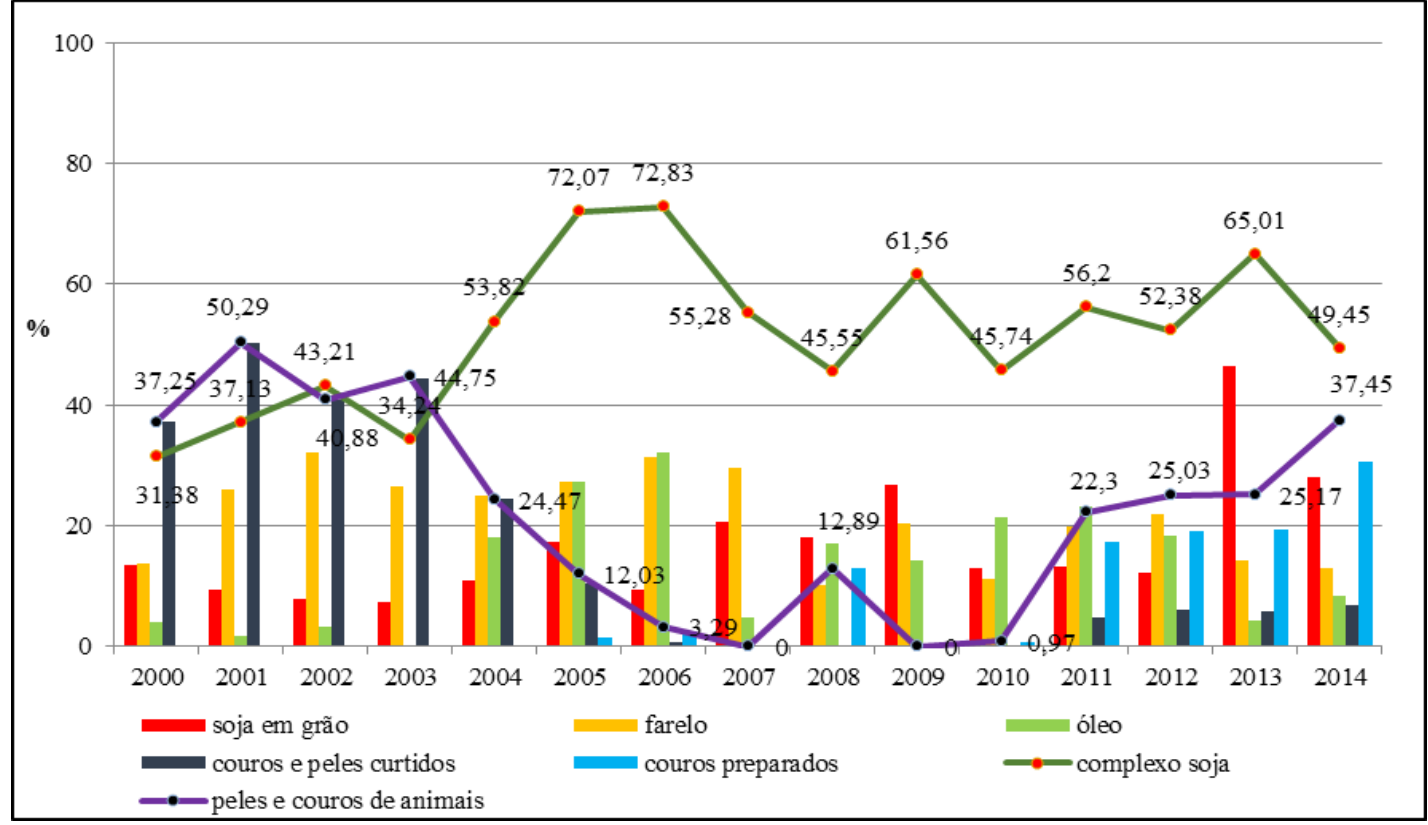

Fonte: DATAVIVA, 2016. Org.: das Autoras, 2016.

O gráfico 1 também permite comparar os dois principais segmentos de exportação pelos respectivos produtos, possibilitando, assim, avaliar a importância destes nas exportações do município. Desta forma, verifica-se que, entre 2000 e 2003, o item “couros e peles curtidos" teve a maior participação nas exportações (entre 37\% e 50\% do total) -participação que pode ser atribuída 
a Brasil Peles e Couros (Braspelco), grande empresa do ramo que atuou no município até meados dos anos 2000 - e foi declinando, sucessivamente, nos anos seguintes, vindo a recuperar-se somente a partir de 2011, atingindo, em 2014, 6,88\%. Já a participação do grupo "couros preparados" foi praticamente nula durante a década de 2000 (com exceção de 2008, quando respondeu por 12,89\% das exportações). Apenas a partir de 2011 o grupo "couros preparados" apresentou um incremento e, em 2014, alcançou 30,57\% das exportações (por sinal, o mais alto percentual registrado ao longo do período), superando todos os demais produtos, o que certamente pode ser atribuído à presença da JBS Couros, instalada em 2010. (EMPRESAS DO BRASIL, 2016).

No conjunto, desde 2004 o complexo soja obteve a maior participação (apesar de uma queda em 2014), permanecendo como o principal segmento de exportação do município, cabendo ao de couros, na maior parte dos anos, o segundo lugar.

A respeito do complexo soja, observa-se que, de 2001 a 2005, o "farelo de soja" foi o artigo que apresentou maior participação (entre 24 e 32\%), com destaque, ainda, em 2006 (quando atingiu 31,4\%, porém não mais como o principal produto), 2007 e 2012 (respectivamente, 29,66\% e 21,95\%). Em relação ao "óleo de soja", houve uma maior participação frente às demais mercadorias apenas nos anos de 2006 (32,08\%), 2010 (21,44\%) e 2011 (23,16\%). Assim, coube à "soja em grãos" o predomínio na pauta exportadora nos anos de 2008 e 2009 (respectivamente, 18,14\% e 26,89\%), e em 2013, quando alcançou 46,39\% do total. Em 2014, caiu para 28,17\% (sendo superada pelos "couros preparados", com 30,57\%), contudo, ainda classifica-se como o principal produto, em comparação aos demais do complexo soja (Gráfico 1).

O complexo carnes (que abrange aves, carnes de aves, suína e bovina, miúdos comestíveis e órgãos de animais) também figurou nas exportações ao longo de todo o período abordado, sendo que, até 2008, a pauta restringiu-se somente à comercialização de aves. Contudo, a partir de 2009, ocorre uma diversificação dos produtos, e um incremento na participação deste ramo, sobretudo através das exportações de carne de aves. (DATAVIVA, 2016).

Tal participação, embora modesta na maior parte dos anos em comparação ao complexo soja e couros, torna-se representativa no contexto 
nacional, por tratar-se do segundo principal segmento de exportação do agronegócio brasileiro. Neste sentido, o aumento das exportações de carnes, após 2009, ocorreu justamente quando a unidade da empresa Sadia, já instalada desde 2000 no município, passou a representar a Brasil Foods (BRF), uma empresa de atuação em escala mundial, vinculada ao comércio de commodities, e única do ramo, até onde se tem notícia, a realizar atividades de exportação em Uberlândia.

Uma vez identificados os principais produtos exportados pelo agronegócio a partir de Uberlândia, procura-se, a seguir, definir os países que mais compram tais mercadorias e, depois, as empresas que se responsabilizam por essas vendas. Espera-se, dessa forma, deixar evidenciadas as relações econômicas articuladas entre o espaço local aqui focalizado e a escala global, bem como reconhecer os principais agentes dessas ações.

\section{A ARTICULAÇÃO LOCAL-GLOBAL POR MEIO DOS SEGMENTOS DE SOJA, CARNES E COUROS}

Ao longo do período abordado (2000-2014), as exportações brasileiras de produtos do complexo soja, carnes e couros destinaram-se, sobretudo, para países europeus e asiáticos, e também para os Estados Unidos.

Segundo informações do Agrostat (BRASIL, 2016), no início da década de 2000, o principal mercado para as exportações do complexo soja consistia na Europa, especificamente Holanda, França, Espanha e Alemanha, países que permaneceram como importantes destinos no decorrer dos anos seguintes. Contudo, em meados da citada década, a China passou a ser o principal comprador de tal segmento, situação esta que permaneceu até 2014. No ramo de couros, os principais importadores, na maior parte do período em foco, foram os Estados Unidos e a Itália, embora a China - país que também já figurava, há alguns anos, como um dos destinos dos produtos deste segmento -, tenha se tornado, no último ano em questão, o mais importante mercado de couros. Quanto às exportações de carnes, os países destinatários mais expressivos foram Rússia, Holanda, Arábia Saudita, Japão e Hong Kong. 
Assim, constata-se que, apesar da permanência da Europa como um importante mercado para as exportações nacionais, é sobretudo ao mercado asiático que o Brasil se encontra vinculado.

É neste contexto que Uberlândia se articula ao comércio de commodities, exportando para vários países e continentes, em escala global. Tal fato pode ser compreendido mediante a análise evolutiva das principais exportações do município e da respectiva distribuição geográfica dos países compradores. A análise foi feita com base nos anos de 2001, 2006, 2010 e 2014, e nos cinco principais destinatários das exportações dos complexos soja e carnes e do ramo de couros, para cada um dos cenários.

Conforme se observa no mapa 1 , no que se refere ao complexo soja, em 2001 as exportações concentraram-se, sobretudo, no continente europeu (respectivamente, na Holanda, França, Hungria e Itália), além da China, a qual se classificou em terceiro lugar nas exportações. Em contrapartida, no ramo de couros - na época o mais importante segmento da pauta exportadora do município -, a Itália figurava como o principal destino e único país europeu a importar produtos deste segmento. Os demais países importadores de couros eram China, Cingapura e Taiwan, o que demonstra uma articulação ao mercado asiático já no início da década de 2000. No ramo de carnes, por sua vez, é o Paraguai que aparece como o único destino das exportações (que se referem a aves).

No ano de 2006, os países europeus ainda prevalecem como importadores de produtos do complexo soja, porém, com Alemanha e Itália em primeiro e segundo lugares, seguidos por Holanda e Grécia, cabendo ao Japão, país asiático, o quinto lugar nas importações. A Itália permanece como o principal destino da indústria de couros, seguida pelos Estados Unidos, Alemanha, China e Indonésia. No segmento de carnes, o Paraguai ainda permanece como o único destino das exportações, de forma análoga ao ano de 2001. Desse modo, no conjunto dos três ramos, verifica-se que, até meados dos anos 2000, as exportações permaneceram concentradas em direção à Europa. (Mapa1). 
Mapa 1- Evolução das exportações de soja, carnes e couros de Uberlândia (MG) -2001 e 2006

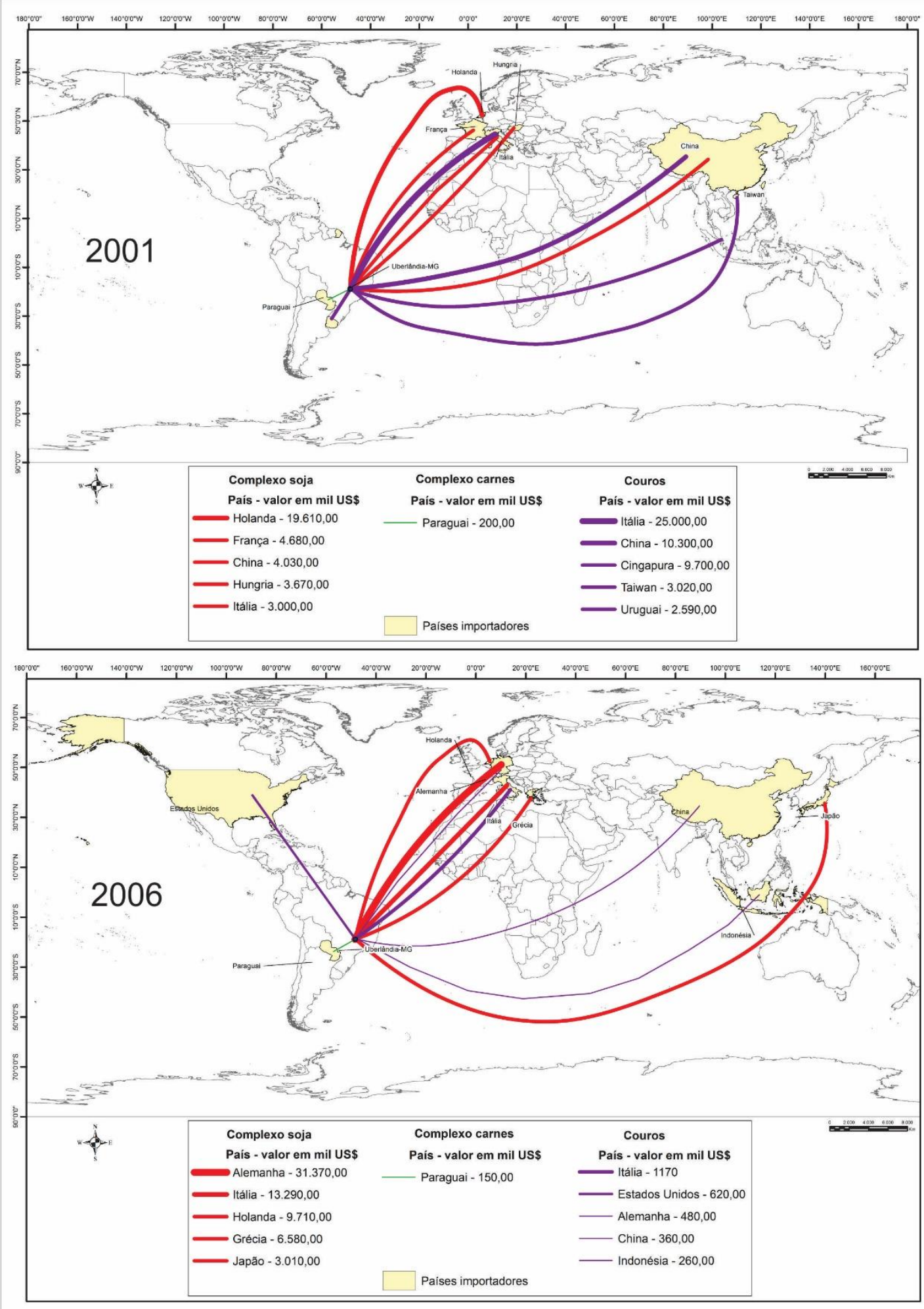

Fonte: DATAVIVA, 2016. Org.: das Autoras, 2016. 
A partir de 2010, com base no mapa 2, pode se observar o deslocamento do fluxo de exportações do continente europeu para o asiático, o qual se tornou o principal mercado para produtos brasileiros dos complexos soja e carnes. A China foi alçada à condição de principal destino das exportações do complexo soja, seguida por França e Holanda (esta, que já havia sido o principal mercado em 2001, permaneceu ao longo dos anos como um importante destino para a soja e derivados). Além do mercado chinês, Tailândia e Irã também constituemse em alguns dos principais destinos para os produtos do complexo soja. No setor de couros, a Itália continuou a ser o principal país importador, seguida pelos Estados Unidos, Hong Kong, Indonésia e Vietnã, o que demonstra um predomínio de países asiáticos. No que concerne ao complexo carnes, houve uma diversificação quanto aos destinos das exportações, por meio de dois países asiáticos já citados, Hong Kong e Vietnã, apesar do Paraguai ter permanecido como um importante mercado.

Em 2014, adensa-se o fluxo das exportações em direção aos países do continente asiático, com aumento, inclusive, no valor das exportações. A China mantém-se como o principal país importador do complexo soja, respondendo por US\$ 100 milhões do valor exportado, assim como desponta em primeiro lugar no comércio de couros. (Mapa 2).

A análise temporal das exportações de Uberlândia, mediante os quatro cenários verificados ao longo do período 2000-2014, demonstra que houve um estreitamento das relações comerciais entre Uberlândia e diversos países asiáticos.

A China (o principal mercado importador de commodities brasileiras, tais como as do complexo soja e couros) fez-se presente, em todos os anos analisados, em pelo menos um dos segmentos citados, alcançando, em 2014, o primeiro lugar em ambos. Todavia, na maior parte do período, além deste país, destacam-se Vietnã, Tailândia, Hong Kong, Indonésia e outros, que também mantiveram relações comerciais com o município. 
Mapa 2- Evolução das exportações de soja, carnes e couros de Uberlândia (MG)

$$
-2010 \text { e } 2014
$$
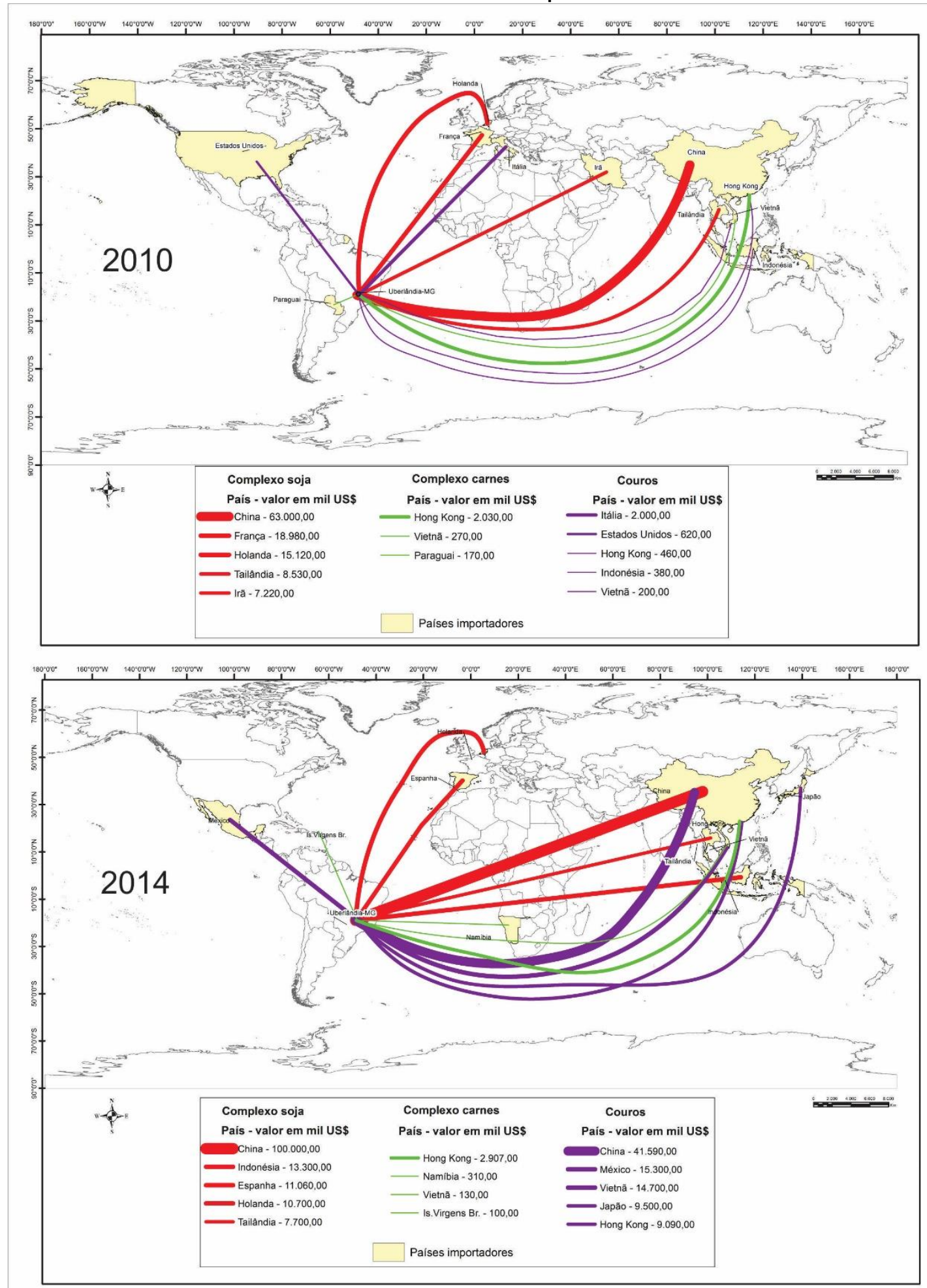

Fonte: DATAVIVA, 2016. Org.: das Autoras, 2016. 
A articulação ao mercado asiático já se evidenciava no início do período abordado, ou seja, em 2001, não somente pela vinculação ao mercado chinês, mas pelas exportações de couros direcionadas à Cingapura e Taiwan. Em 2006, os laços com os países asiáticos se sustentam através do Japão (no complexo soja) e da China e Indonésia (no ramo de couros), todos os três com uma participação menor em comparação aos países europeus (Mapa 1).

Com base no mapa 2, verifica-se que, em 2010, a China já se apresentava como o principal destino do complexo soja (cujo valor das exportações chega a US\$ 63 milhões), e esse desempenho, somado às participações de Tailândia e Irã, colocam o continente asiático à frente dos demais na demanda por produtos deste segmento. Outros dois países asiáticos que despontam como os principais destinos das exportações são Hong Kong e Vietnã, tanto do complexo carnes como de couros, este último ramo contando, também, com o mercado da Indonésia. Em 2014, este país representava o segundo maior mercado de soja e derivados, logo após a China, assim como a Tailândia permanece no rol dos principais destinos destes produtos. No complexo carnes, Hong Kong - que, seguindo a tendência nacional, ocupa o primeiro lugar - e Vietnã permanecem como importadores deste segmento, assim como também compõem, juntamente com a China e o Japão, o mercado asiático para o segmento de couros.

No que se refere ao complexo carnes, vale destacar ainda, que, apesar do valor exportado ser menos expressivo em comparação aos outros segmentos, os dois últimos cenários analisados (Mapa 2) se inserem no contexto de diversificação deste setor no município, que passou a exportar também carne de aves, refletindo a ampliação do mercado externo para este produto e a crescente demanda de países asiáticos pelas exportações brasileiras. (Mapa 2).

Por outro lado, quanto ao complexo soja, mesmo com o predomínio da China como destino das exportações, o vínculo com o mercado europeu permanece, sobretudo através da Holanda, a qual, após ocupar a primeira posição em 2001, se manteve, durante todos os demais anos analisados, como um dos principais mercados (apesar de uma queda relativa na participação). Tal fato condiz com a pauta exportadora nacional, na qual este país vem ocupando a segunda colocação (DATAVIVA, 2016). Além da Holanda, no tocante ao 
continente europeu, França e Espanha mantiveram-se como destino das exportações do ramo de soja.

Ainda com respeito à Europa, a Itália (além de classificar-se, até 2006, como um dos destinos do complexo soja) destacou-se como principal país importador de couros nos três primeiros anos analisados, posição que, em 2014, passou a ser ocupada pela China (Mapas 1 e 2). Apesar de não estar mais entre os cinco primeiros consumidores, a Itália continuou a ser um dos destinos das exportações de couros do município (DATAVIVA, 2016), assim como um dos principais mercados do país. De forma análoga, os Estados Unidos, que vinham ocupando, desde 2006, o segundo lugar nas exportações de couros (e o primeiro no país), também não figuram mais, em 2014, entre os principais destinos, cedendo lugar ao México (Mapa 2). Em nível nacional, a China consiste no maior importador de couros, cabendo aos Estados Unidos e Itália, respectivamente, a segunda e terceira colocações (DATAVIVA, 2016).

A referida articulação do município ao comércio internacional de commodities ocorre por meio da atuação das empresas processadoras de soja (Cargill e ADM, ambas de origem estadunidense), de carnes (Brasil Foods, empresa nacional) e de couros (JBS Couros, também nacional), fato que pode ser comprovado, com base nas seguintes constatações:

- As agroindústrias Cargill, ADM, Brasil Foods e JBS Couros comercializam seus produtos para diversos países, muitos dos quais representam os principais destinos das exportações do município;

- Segundo informações do Centro Industrial e Empresarial de Minas Gerais (CIEMG, 2013) a Cargill e a ADM exportam para a China, o principal importador de produtos do complexo soja. No caso da Cargill, além deste país, a empresa exporta seus produtos para Alemanha, Holanda, França, Itália, Arábia Saudita e Japão, os quais também correspondem aos principais destinos das exportações de soja e derivados do município;

- Ainda com respeito às empresas Cargill e ADM, ambas têm os Estados Unidos como um de seus mercados consumidores (CIEMG, 2013) o qual importou soja em grão do município por vários anos (2003, 2004, 2006 a 2008 e 2014) (DATAVIVA, 2016), embora não se classifique entre os principais destinos das exportações do complexo soja; 
- No tocante à Brasil Foods - reconhecida nacionalmente como uma das principais empresas exportadoras de carnes de aves -, apesar de segundo CIEMG (2013), a unidade exporte somente para a Romênia, supomos que a companhia também comercialize seus produtos para os principais destinos das exportações revelados, tal como Hong Kong, que desponta, desde 2010, como o maior importador de carnes do município (época em que a empresa passou a atuar no espaço local). Além disso, conforme o sítio eletrônico da Brasil Foods (BRF, 2015), o referido país consiste num dos mercados em que o grupo empresarial vem atuando no continente asiático.

- Quanto ao ramo de couros, na primeira metade dos anos 2000, os principais destinos deste segmento (Itália, China e Estados Unidos) eram os mesmos mercados da empresa Braspelco (BRASPELCO..., 2003). Já nos anos de 2010 e 2014, as exportações relacionam-se à presença da JBS Couros, pois, dentre os países para o qual a empresa exporta (JBS, 2015), encontram-se os principais destinos do couro exportado pelo município, quais sejam, Itália, China e México. (Mapa 2).

Pelo exposto, constata-se que a articulação de Uberlândia ao mercado globalizado de commodities abrange países de localizações e níveis de desenvolvimento diversos, haja vista a participação tanto de países desenvolvidos (como Estados Unidos, Itália e Japão) como de economias emergentes (China e Indonésia). A referida articulação ocorre por meio do comércio de gêneros primários e semimanufaturados, significando que o "local" ora analisado apresenta forte dependência da atividade agropecuária e agroindustrial.

A análise dos quatro cenários, ao longo das décadas de 2000 e 2010, confirmou que houve uma intensificação da especialização produtiva do município, em gêneros agropecuários e agroindustriais, fato atribuído à crescente inserção do Brasil no mercado global de commodities. A concentração de empresas agroindustriais pertencentes a grandes grupos econômicos, em uma fase de expansão da demanda internacional por produtos como os dos complexos soja, carnes e os couros, acabou expandindo a capacidade de produção do espaço local, intensificou a especialização produtiva e consolidou a articulação do território à esfera econômica global. 


\section{CONSIDERAÇÕES FINAIS}

A literatura pertinente nos mostra que a articulação econômica de um local com a escala global se concretiza pela ação conjugada de fatores e/ou forças endógenas e exógenas aos lugares. Geralmente, o estímulo inicial é emitido da escala global: o aumento da demanda de um ou vários produtos provoca sua valorização e os espaços que têm condições de produzi-los (no setor agrícola ou no industrial), e/ou que já apresentam tradição nessas produções, passam a elevar a produção e a intensificar sua especialização produtiva. É o local reagindo aos estímulos externos, e essa ação conjugada de agentes internos e externos possibilita que as articulações local-global se iniciem, ampliem ou sejam reestruturadas.

A análise aqui desenvolvida constitui, a nosso ver, um exemplo cabal dos processos acima relacionados. No caso de Uberlândia, as políticas nacionais de incentivo às exportações e a gradativa inserção brasileira ao mercado global de commodities agrícolas e agroindustriais vieram estimular uma atividade que já se mostrava historicamente consolidada no município, fazendo com que se ampliasse muito a escala de produção e se intensificasse a especialização produtiva do território. Grandes empresas de capitais nacionais e internacionais e poder público foram os principais agentes responsáveis por tais ações.

Como um efeito negativo de tal conjunção de fatores externos e internos ao lugar, registre-se o fato de que tem sido apontada, por estudiosos do tema, uma reprimarização da pauta exportadora do país, processo bastante preocupante, já que ocorre correlatamente a uma redução da exportação de bens industriais de alta e média tecnologias, ou seja, estaria em curso um processo nacional de retrocesso econômico.

\section{REFERÊNCIAS}

ADM. Archer Daniel Midlands. Disponível em: < www.adm.com/ptBR/worldwide/brazil/> . Acesso em: junho de 2015 .

BENKO, G.; PECQUEUR, B. Os recursos de território e os territórios de recursos. Geosul, Florianópolis, v.16, n.32, p 31-50, jul./dez. 2001.

BRASIL Ministério da Agricultura, Pecuária e Abastecimento (MAPA).

Agrostat. Brasilia, 2016. Disponível em: <http://indicadores.agricultura.gov.b r/agrostat/index.htm.>Acesso em: 11 de março de 2016. 
BRASPELCO inaugura a maior fábrica de couro do mundo. Diário de Cuiabá, 12 out. 2003. Disponível em:<http://www.diariodecuiaba.com.br/detalhe.php? cod=156912. $>$ Acesso em: 27 de novembro de 2015 .

BRF. Brasil Foods. Disponível em: <http://www.brf-global.com/brasil> Acesso em: junho de 2015.

CARGILL. Cargill. Disponível em: < http://www.cargill.com.br/pt/sobrecargill-brasil/perfil-global/index.jsp>. Acesso em: junho de 2015.

CENTRO INDUSTRIAL E EMPRESARIAL DE MINAS GERAIS-CIEMG. Cadastro industrial de Minas Gerais, 2013.1 CD-ROM.

DATAVIVA. Data viva. Disponível em: < http://pt.dataviva.info/>. Acesso em: fevereiro de 2016.

EMPRESAS DO BRASIL. Disponível em:<http://empresasdobrasil.com/>. Acesso em: mar. 2016.

JBS. JBS. Disponível em: < http://www.jbs.com.br/pt-br/sobre_jbs $>$ Acesso em: junho de 2015.

MASSEY, D. Spatial divisions of labour: social estructures and the geography of production. $1^{\text {a }}$ edição. London: Macmillan, 1984.

Pelo espaço: uma nova política da espacialidade. Rio de

Janeiro: Bertrand Brasil, 2008. 312 p.

SANTOS, M. A natureza do espaço: técnica e tempo, razão e emoção. $4^{\mathrm{a}}$ edição. São Paulo: Hucitec, 2006.

Técnica, espaço, tempo: globalização e meio técnicocientífico-informacional. São Paulo: Hucitec, 1997.

SELINGARDI-SAMPAIO, S. Indústria e território em São Paulo: A estruturação do multicomplexo territorial industrial paulista. Campinas: Alínea, 2009.

SILVEIRA, M. L. A Uma teoria geográfica da sociedade: razão global e razão local. In: CARLOS, A.F.A. (Org.) Ensaios de geografia contemporânea. São Paulo: Hucitec, 1996. p. 63-72.

Recebido em 12 de agosto de 2020

Aceito em 04 de setembro de 2020 